\title{
Problematic topic transitions in dysarthric conversation
}

\section{STEVEN BLOCH ${ }^{1}$, CHARLOTTA SALDERT $^{2} \&$ ULRIKA FERM $^{3}$} Institute of Neuroscience and Physiology, University of Gothenburg, Gothenburg, Sweden, and ${ }^{3}$ DART - Centre for AAC and 64

\section{Abstract}

Purpose: This study examined the nature of topic transition problems associated with acquired progressive dysarthric speech in the everyday conversation of people with motor neurone disease.

Method: Using conversation analytic methods, a video collection of five naturally occurring problematic topic transitions was identified, transcribed and analysed. These were extracted from a main collection of over 200 other-initiated repair sequences and a sub-set of 15 problematic topic transition sequences. The sequences were analysed with reference to how the participants both identified and resolved the problems.

Result: Analysis revealed that topic transition by people with dysarthria can prove problematic. Conversation partners may find transitions problematic not only because of speech intelligibility but also because of a sequential disjuncture between the dysarthric speech turn and whatever topic has come prior. In addition the treatment of problematic topic transition as a complaint reveals the potential vulnerability of people with dysarthria to judgements of competence.

Conclusion: These findings have implications for how dysarthria is conceptualized and how specific actions in conversation, such as topic transition, might be suitable targets for clinicalintervention.

Keywords: Dysarthria, conversation analysis, neurodegenerative diseases

\section{Introduction}

People with moderate-to-severe speech intelligibility problems arising from motor speech problems (dysarthria) and their communication partners can experience a range of difficulties in everyday conversation (Bloch \& Wilkinson, 2009; Griffiths, Barnes, Britten, \& Wilkinson, 2011; Rutter, 2009). Such difficulties, or what we will call troubles, are rooted in unintelligible speech but can also relate to the understandability of the talk (Bloch \& Wilkinson, 2004, 2013); that is, how a turn or utterance is understood in relation to whatever has come prior. Is it also conceivable that troubles with dysarthria in conversation may not be randomly distributed but may be associated with a specific place or activity in that conversation.

\section{Troubles and repair in dysarthria}

In everyday conversations involving unimpaired speakers, speech and language rarely are produced without problems or errors. It is common to experience troubles in speaking, hearing or understanding talk in conversation (Schegloff, 1997). Participants themselves display these problems or troubles by asking for repeats, asking for clarification of meaning and re-starting words already underway. The term repair describes the practices used by participants to highlight and then deal with or manage troubles within interaction. Repair itself is designed for efficiency and successful resolution of problems when they arise (Schegloff, 1979). The practices of repair and the troubles on which they operate in non-impaired speakers have been well documented in terms of organization (Schegloff, Jefferson, \& Sacks, 1977), format (Drew, 1997) and operations (Schegloff, 2013). One of the key organizational features is the distinction between repair initiation and repair completion. This distinction reflects the potential involvement of the speaker of a trouble source (self) and/or the recipient of a trouble (other). Involvement of either or both participants in 106 repair reveals much of the nature of the problem 107

Correspondence: Dr Steven Bloch, University College London, Language and Communication, 2 Chandler House, Wakefield Street, London WC1N 1PF, UK. E-mail: s.bloch@ucl.ac.uk

ISSN 1754-9507 print/ISSN 1754-9515 online (C 2014 The Speech Pathology Association of Australia Limited Published by Informa UK, Ltd.

DOI: $10.3109 / 17549507.2014 .979879$ 
and how participants organize their actions to achieve resolution.

Dysarthria in conversation is manifest through the occurrence of troubles and their repair. It is for this reason that, to date, repair has been a central feature of interest in research on the everyday conversation practices of people with dysarthria. This is important because, whilst most non-speech impaired troubles are typically resolved in the same turn of talk or at the next opportunity after that turn (Schegloff et al., 1977), troubles with dysarthric speech can extend over a large number of turns (Bloch \& Wilkinson, 2009, 2013). This may have implications for understanding and treating the impact of dysarthria in different interactions.

To date the conversations of two groups of people with dysarthric speech have been investigated: those with developmental dysarthria arising from cerebral palsy (Clarke \& Wilkinson, 2007; Clarke, Bloch, \&Wilkinson, 2013; Collins \& Markova, 1999) and those with acquired dysarthria arising from neurological diseases such as motor neurone disease (MND) (Bloch \& Wilkinson, 2004, 2009, 2011, 2013), Parkinson's disease (Griffiths et al., 2011; 2012; Saldert, Ferm, \& Bloch, 2014), multiple sclerosis (Rutter, 2009, 2010) and Huntington's disease (Saldert \& Hartelius, 2011). For the acquired group in particular the management of problems is notable with reference to adult peer judgements of competence and responsibility.

Previous work demonstrates that trouble sources identified by a recipient using an other-initiation of repair (OIR) are a regular feature of conversations featuring speakers with dysarthria (Bloch, 2006; Bloch \& Wilkinson, 2004, 2009; Collins \& Markova, 1995). It has been established that dysarthric troubles in conversation are not only a result of unintelligible speech. Rather, the problems that recipients can be seen to experience in these conversations have been described more generally as problems with understandability (Bloch \& Wilkinson, 2004); that is, a difficulty for a recipient in understanding something about a prior turn as displayed by his/her launching of some type of otherinitiated repair activity. While the intelligibility issues created by dysarthria are regularly a significant factor in creating difficulties with the understandabilty of these turns, other features of these turns can also be seen to be important. For example, it has been noted that, in conversation generally, an important issue in a listener understanding a turn is that $\mathrm{s} / \mathrm{he}$ grasps the sequential relationship between that turn and the turns immediately preceding it (Drew, 1997). This can be a problem for speakers with dysarthria and their recipients, including utterances produced using AAC (augmentative and alternative communication) devices such as VOCAs (voice output communication aids).
In these cases, recipients may have difficulty under- 61 standing a VOCA-produced utterance due to the 62 fact that, even when each of the words is intelligible 63 to them, the slowness in producing the utterance 64 means they cannot always understand the sequen- 65 tial relationship between that utterance and what 66 has preceded it (Bloch \&Wilkinson, 2004). Further 67 problems relating to the understandability of the 68 speaker with dysarthria's turn can arise if the recip- 69 ient misinterprets or fails to grasp what it is about 70 the speaker with dysarthria's turn which is making 71 it difficult to understand (Bloch \& Wilkinson, 72 2009). This can lead to additional problems in 73 completing the repair, with these problems intensi- 74 fied if in turn the speaker with dysarthria does not 75 perceive that the recipient is having difficulty in 76 understanding what the exact nature of the trouble 77 is (Bloch \& Wilkinson, 2009). 78

Topic organization and topic change in conversation

Topic in conversation is commonly understood as 82 a particular subject or thing being talked about, 83 such as the weather or holidays; that is, the prop- 84 erty of content. Whilst the status of topic remains 85 problematic in its own right for studies of conversa- 86 tion (Schegloff, 1979), it may be considered 'an 87 achievement of conversationalists, something orga- 88 nized and made observable in patterned ways that 89 can be described' (Maynard, 1980, p. 263). From 90 this perspective, topic in conversation can be 91 understood as a participant organized process or 92 procedure rather than simply what is being talked 93 about. We may then usefully question how topic 94 works in conversation rather than just what topics 95 are talked about.

Topic change or the transition between topics is 97 open to analysis (Button \& Casey, 1988/89) given 98 that participants need to observably organize tran- 99 sitions by using, for example, recognizable termina- 100 tions such as figurative speech (Drew \& Holt, 101 1998), openings such as 'so' (Bolden, 2009) or 102 topic initial elicitors such as 'anything else to report' 103 (Button \& Casey, 1984). Topic change may be dis- 104 junctive/boundaried (Sacks, 1992) or progress in a 105 more step-wise fashion (Jefferson, 1984a). Irre- 106 spective of how it operates, identifying topic initia- 107 tion may not always be obvious, particularly as 108 topics often flow from one to another without a 109 new topic being introduced explicitly (Button \& 110 Casey, 1985).

It is also the case that topic initiation may be par- 112 ticularly vulnerable to problems. Schegloff (1979) 113 observes that, of first sentences (sic) in topic-initial 114 turns or in topic shift position, it is the case that they 115 very regularly have self-repair in them (and at a spe- 116 cific point, i.e., the word that keys the new topic 117 being initiated). Additionally, if first sentence in top- 118 ic-initial or topic shift position does not have self- 119 initiated repair, then with great frequency the 120 
next-turn involves the initiation of repair by some other. This raises the question of whether certain places within conversation are more vulnerable to troubles than others and, if so, how participants manage these troubles.

We have observed that attempts at topic-transition by speakers with dysarthria can be prone to troubles, as indicated by conversation partner responses. In addition, we note that recipients of these attempted transitions often employ explicit meta-communicative statements as part of their repair work such as 'are we talking about $\mathrm{X}$ or $\mathrm{Y}$ ?' Such statements display topic as both the trouble source and a potential route to resolution. This has parallels with the analysis of topic talk featuring other disorders such as aphasia (Barnes, Candlin, \& Ferguson, 2013; Laakso \& Klippi, 1999; Wilkinson, Lock, Bryan, \& Sage, 2011) and dementia (Garcia \& Joanette, 1997; Orange, Lubinski, \& Higginbotham, 1996).

\section{Fault and responsibility in repair}

One further aspect of dysarthric conversation that has, to date, received little attention is that of fault and responsibility. Robinson (2006) highlights the sensitivity of trouble responsibility in conversation and the potential role that either or both participants may play in its ownership and management. Robinson focuses on open class repairs (Drew, 1997) in which different accounts are provided such as an apology + account as in I'm sorry I couldn't hear you there's so much noise, thus invoking the recipient's hearing as the fault. He argues that the apology-based OIR format is a context-sensitive practice for managing trouble responsibility by communicating repair-initiators' stance that trouble responsibility belongs to themselves, rather than to their addressees.

For OIR in particular the notion of who is to blame for the trouble may have both organizational and moral consequences. In the case of people with communication disabilities this moral vulnerability may be of heightened importance (Barnes \& Ferguson, 2014). It may also reflect on the perceived competence of the co-participant.

In summary, it is well established that people with dysarthria and their communication partners experience problems in managing intelligibility. These problems arise because of speech/hearing signal disruptions but can also include difficulties in establishing the relationship between one turn and another. Topic transition boundaries may be particularly vulnerable to problematic understandings. These problems may also be prone to challenges of competency. In what follows we present a set of Extracts in order to examine different features of naturally occurring problematic topic transitions within an environment of dysarthric conversations.
Methods

Design

62

63

The present research utilized a longitudinal qualita- 64 tive approach based on the methods and principles 65 of Conversation Analysis (Sidnell, 2010). 66

Sampling and participants

69

The data presented here were obtained as part of a 71 larger ethnographic study program examining interac- 72 tion between people with progressive neurological dis- 73 eases and close family members. Purposive sampling 74 was used to select 12 participants. The study popula- 75 tion was people with dysarthric speech and a con- 76 firmed diagnosis of either motor neurone disease 77 (MND), Parkinson's disease or multiple sclerosis 78 (MS). People with clinically diagnosed cognitive and/ 79 or language disorders were excluded from the study. A 80 summary of three participants, whose data appear in 81 this paper, follows with pseudonyms used to preserve 82 anonymity. These three were chosen to represent dif- 83 ferent dyad profiles of dysarthria in interaction (Bloch, 84 2013), ranging from moderate to severe dysarthria. 85

Mary, 65, was diagnosed with MND $\sim 24$ months 86 prior to the study and was recorded in conversation 87 at home with her husband Stan, 70. Extract 2 was 88 selected from recording 3 (9-months into the study) 89 and Extract 3 from recording 4 (12-months into the 90 study). During these periods, Mary presents with 91 moderately hypernasal speech with reduced respira- 92 tory support and variable precision of tongue func- 93 tion for sound production. Her voice has a strangled 94 quality and her pitch range is reduced. Mary's pala- 95 tal, laryngeal and tongue functions are notably 96 reduced on all clinical assessment parameters. Dur- 97 ing both recordings she makes use of a LightWriter?? 98 voice output communication aid (VOCA) to aug- 99 ment her existing communication abilities. $\quad 100$

Alex, 38, was diagnosed with MND 12 months 101 prior to data collection and was recorded in conver- 102 sation at his nursing home with his mother Molly, 103 61. Extract 4 was selected from recording 2 (6-months 104 into the study) and Extract 6 from recording 4105 (12-months into the study). Alex has significantly 106 impaired motor speech abilities and both upper and 107 lower limb mobility problems. He neither reports nor 108 displays any language or cognitive difficulties. At 109 recording 2 he retains some residual speech ability 110 (restricted to single word output due to respiratory 111 limitations) but by recording 4 his expressive output 112 is reliant on an onscreen virtual keyboard (EZ Keys 113 by Words + ) operated via a head-switch.

Jean, 68, was diagnosed with MND 18 months 115 prior to data collection and was recorded in conver- 116 sation at home with her daughter Ali, 37. Extract 1117 was selected from recording 1 (at the start of the 118 study) and Extract 5 was selected from recording 2119 (3-months into the study). Throughout the study 120 
Jean presents with a severe mixed spastic-flaccid dysarthria characterized by aphonia, poor breath support and overall articulatory weakness. Aside from gross vocalization, Jean's speech is non-functional.

The communication abilities of all communication partners in the study are observed to be within normal limits with no reported language, cognitive or sensory problems.

\section{Procedure}

Approval for the study was awarded by a UK National Health Service (NHS) Research Ethics Committee. Participants were then recruited through their NHS speech-language pathology service. The couples were loaned standard video camera equipment and were instructed in its use. They were asked to record themselves for $\sim 30$ minutes within an agreed 1-week sampling period. It was requested that the recording take place during a regular opportunity for everyday conversation such as at a meal or coffee time. This process was repeated at 3-monthly intervals \pm 1 week over a 12-month period. This design was used to capture any potential changes over time. Features of change will be presented in future publications.

\section{Analysis}

The video data were transcribed according to common CA conventions (Jefferson, 1984b) and then different patterns of interaction were identified through numerous reviews of the data and transcripts. This inductive, data-led process was led by the first author with contributions from several group data sessions with other CA researchers. A collection of over 200 other-initiated repairs was identified. Within this collection a topic initiation and transition sub-set was examined. A more detailed analysis of problematic topic transition talk followed. This involved scrutiny of the placement, design and organization of 15 problematic topic transition sequences. Five of these sequences were then selected to exemplify different phenomena within the data. Each transcript was developed by the authors during a series of data sessions through which any errors in hearing or viewing were identified, examined and corrected as required. This resulted in a $100 \%$ agreement between the authors. These five sequences are presented below.

\section{Results}

We will present an unproblematic example followed by five sequences featuring attempted topic-transition turns by people with dysarthria. We will also consider where these turns occur and the ways in which conversation partners signal the nature of the trouble. We will show that the troubles are characterized by a disjunctive relationship between the current turn's topic and whatever has come immediately prior.
These troubles are situated at the point where the 61 person with dysarthria is attempting to introduce 62 something designed to be heard as distinct from the 63 prior topic. Further, in many of the Extracts the con- 64 versation partner invokes topic ambiguity as part of 65 the repair activity, displaying an explicit orientation 66 to topic in order to progress to resolution of the trou- 67 ble. A key to the CA transcription conventions used 68 below is provided in the Supplementary Appendix to 69 be found online at http://informahealthcare. com/doi/ 70 abs/10.3109/17549507.2014.979879. 71

$\begin{array}{ll} & 72 \\ & 73\end{array}$

Unproblematic topic transition

Extract 1-going back to

In the first Extract, Ali and Jean have been talking 76 about a friend's grandchildren and school dates. Ali 77 then signposts a clear topic transition through her 78 announcement 'going back to' (line 10).

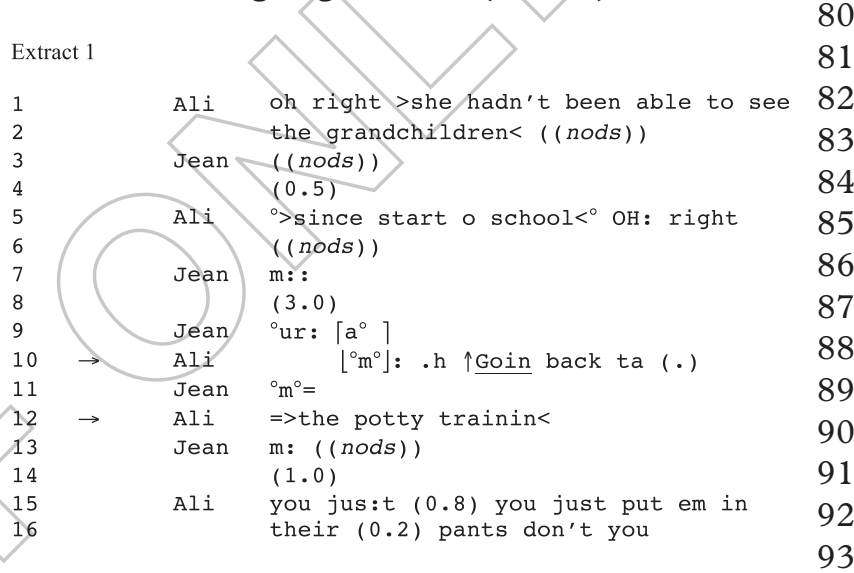

The talk in Extract 1 begins with Ali's receipt of a 94 prior written contribution by Jean. 'Oh right' at 95 lines 01 and 05 reveals the newsworthiness of Jean's 96 contribution. A 3-second silence is followed by 97 Jean's turn initiation, but is interrupted by Ali with 98 her own talk at line 10. With 'going back to' Ali 99 displays an explicit reference to talk that has come 100 previously, but not immediately prior, in the con- 101 versation. This misplacement marker (Schegloff \& 102 Sacks, 1973) alerts Jean not to hear or understand 103 the following talk as fitting with what has just been 104 said.

Ali then pauses, providing an opportunity for Jean to 106 produce a brief acknowledgement turn and to display 107 her understanding that more is to follow, specifically a 108 topic of talk that has already been addressed previously 109 in this or a recent conversation. Ali then specifies the 110 topic itself: potty training (line 12). This announcement 111 is followed by Jean giving the go-ahead to proceed 112 before Ali offers her comment on the topic in hand. 113

Here Ali's use of a misplacement marker links her 114 current talk to a previous topic and designs it to be 115 heard by Jean as disjunctive from that just addressed, 116 namely talk about grandchildren. In this way, both 117 Jean and Ali are ready to proceed with talk about 118 potty training. The risk of topic disjuncture as a 119 potential trouble source has been minimized 120 
through the organized management of topic transition.

\section{Problematic topic transition}

\section{Extract 2-double glazing}

In Extract 2, Mary, with moderate/severe dysarthria, attempts to introduce a new topic to the conversation. This arises following prior topic closing talk by Stan. The prior topic concerns the current installation of double-glazing at Stan and Mary's house. The new topic relates to a craft-box she has made and bought home from her day-centre, St Floribus. Mary's turn and topic initiation is clearly shown by Stan to be unintelligible and results in an extended repair sequence. On understanding that Mary is attempting to introduce a new topic Stan makes a mock-tease complaint about the lack of relevance to the prior topic of double-glazing.

\section{Extract 2}

\begin{tabular}{|c|c|c|c|}
\hline 01 & & Stan & and er $(2.9)$ yeah I'll be glad to see it all \\
\hline $\begin{array}{l}02 \\
03\end{array}$ & & & $\begin{array}{l}\text { finished. } \\
(0.3)\end{array}$ \\
\hline 04 & & Mary & $\mathrm{m}: \mathrm{m}$ \\
\hline 05 & & & $(1.2)$ \\
\hline 06 & & Stan & then we cun move on to other things $=$ \\
\hline 07 & & Mary & \\
\hline 08 & & & $(1.9)$ \\
\hline 09 & & Mary & ((opens mouth $)){ }^{\circ} \mathrm{h}[(0.2)$ w] hat \\
\hline 10 & & Stan & $\lfloor\mathrm{coz}$ er $\rfloor$ \\
\hline 11 & & & $(2.0)$ \\
\hline $\begin{array}{l}12 \\
13\end{array}$ & & Mary & $\begin{array}{l}\text { what a nice }(0.7)(\text { box })(0.7)(f \text { : rom saint } f) \\
(1.1)\end{array}$ \\
\hline $\begin{array}{l}14 \\
15\end{array}$ & & Mary & $\begin{array}{l}\text { (a: bo brought }(0.4) \text { home.) } \\
(1.4)\end{array}$ \\
\hline 16 & & Mary & 「with the glitter \\
\hline 17 & & & {$[(($ mimes box shape $))]$} \\
\hline 18 & & & $(1.3)$ \\
\hline 19 & & Mary & $\Gamma \mathrm{m}:$ \\
\hline 20 & & & L( (mimes box sha \\
\hline 21 & & & $(2.0)$ \\
\hline $\begin{array}{l}22 \\
23\end{array}$ & $\rightarrow$ & $\begin{array}{l}\text { Stan } \\
\text { Mary }\end{array}$ & ${ }^{\circ}$ in the ${ }^{\circ} \mathrm{s}$ \\
\hline 24 & & Stan & say it aga \\
\hline 25 & & Mary & ((moves glass, rea \\
\hline 26 & & & [(four syllables) \\
\hline 28 & & & $\begin{array}{l}\text { L(moves } \\
(2.5)\end{array}$ \\
\hline 29 & $\rightarrow$ & Stan & what $()$. \\
\hline 30 & & Mary & $=\mathrm{m} \quad \mathrm{m} \mathrm{m}:$ \\
\hline 31 & $\rightarrow$ & Stan & =what abou \\
\hline 32 & & Mary & $\begin{array}{l}=((\text { VOCA On })) \# \\
{[(1,2) \# \#}\end{array}$ \\
\hline 34 & $\rightarrow$ & Stan & my (1.1) my double 」 \\
\hline 35 & & & $g_{1}$ \\
\hline 36 & & Mary & $=(($ smiles and looks to $S)){ }^{\circ} \mathrm{h}-{ }^{\circ} \mathrm{no}^{\circ}$ \\
\hline 37 & & & {$[(($ shakes head $))]$} \\
\hline 38 & & Stan & 「h-heh? \\
\hline 39 & & & {$[(($ smiles $))]$} \\
\hline 40 & & Mary & noho-thing: \\
\hline 41 & & & {$[(($ shakes head $))]$} \\
\hline
\end{tabular}

Following the closure of the prior topic (lines 01-07) there is a lengthy silence in the talk at line 08 before Mary takes an audible in-breath. In the pause between this breath and her saying 'what', Stan overlaps with his own turn initiation. There is then further silence before Mary re-starts her turn. What Mary says is largely unintelligible, as evidenced by the lack of uptake by Stan in next turn positions (13, 15 and 21) as well as Mary's self-repair attempt mimes (lines 17 and 20). The upshot is Stan's other initiation of repair (line 22). His request to 'say it again' adds weight to the interpretation that he can- not continue without a repeat or reformulation of 61 Mary's prior utterance. 62

Mary now reaches for her VOCA, presumably to 63 assist her self-repair attempt. Whilst this activity is 64 underway, Stan offers a guess as to a possible refer- 65 ence within Mary's talk (line 29). The design of this 66 candidate reference serves to contribute to the 67 attempted repair resolution and to make explicit the 68 nature of the trouble, namely the reference of Mary's 69 talk. Stan has been able to identify St Floribus as a 70 possible reference in Mary's first trouble source 71 turn at line 12 , but his talk at line 31 reveals his 72 inability to understand to what the reference St Flo- 73 ribus is contributing at that point. Mary begins to 74 type on her VOCA but, given the non-vocal nature 75 of this activity, it is possible for Stan to contribute 76 further talk without verbal overlap (Clarke \&Wilkin- 77 son, 2007). He does exactly this at line 34 by asking 78 Mary to justify or account for the relationship 79 between her talk in progress, concerning St Flori- 80 bus and the most recently addressed topic concern- 81 ing double-glazing. This is despite the fact that it is 82 Stan who has closed the prior topic down. The sur- 83 rounding laughter by Stan and Mary's laughed 84 through response indicates that this question has 85 been neither designed nor received as a serious 86 enquiry. The idiomatic/teasing flavour of Stan's 87 mockjustification request provides further evidence 88 $\begin{array}{ll}\text { of his non-serious intent. } & 89\end{array}$ Implicit in Stan's turn: 'what's this got to do with 90 my double glazing' is a complaint about Mary's 91 unannounced attempt to change what is being 92 talked about. It is perhaps this absence of a hearable 93 or explicitly marked signpost as displayed so clearly 94 in Extract 1 that provides insight into Stan's action. 95 $\mathrm{He}$ is complaining, non-seriously, that Mary is 96 doing something that is causing him a problem. 97 This places responsibility for the trouble with Mary 98 and calls her to account for it (Robinson, 2006). 99 Mary's retort with a humorous 'nothing' (line 40) 100 is perhaps entirely fitting and avoids the need for 101 her to justify this topic transition any further. It also 102 enables her to return to the self-repair activity 103 already underway. 104

Extract 3-the painting. In Extract 3, Mary attempts 106 to make reference to a jigsaw-painting craft activ- 107 ity with which she has recently engaged. Her first 108 attempt to establish this topic talk is unsuccessful 109 but she returns to the same topic following 110 intervening talk, introduced by Stan, about her 111 voice and swallowing problems. The subsequent 112 return to jigsaw-painting talk proves problematic, 113 with Stan invoking a prior topic as a possible 114 interpretative reference point during the repair 115 sequence.

The following episode appears at the very begin- 117 ning of the recording, with no immediately prior talk. 118 Stan has just sat down, having turned on the video 119 camera to record. 


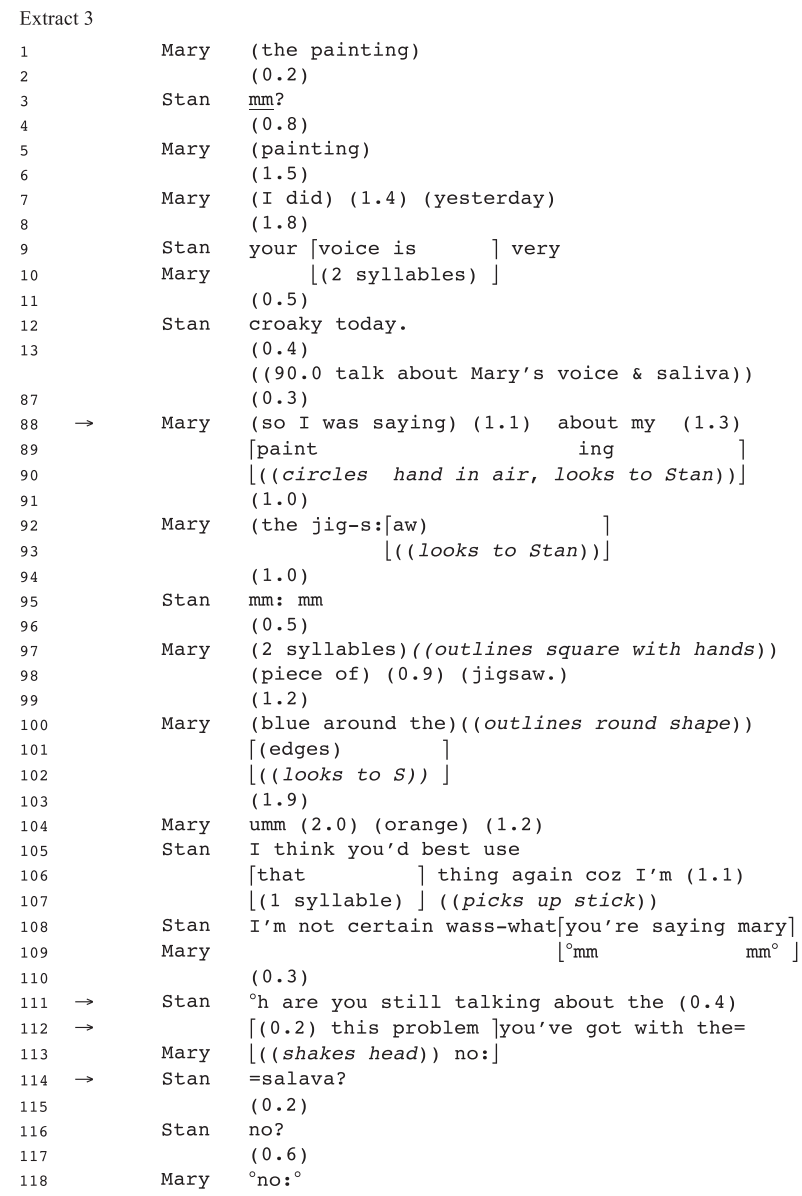

At the beginning of this sequence Mary attempts to introduce a new topic. Given her level of dysarthria, which is more severe than the speech observed in Extract 2, she does this through the production of just two words: the painting. Through his open class repair initiator (Drew, 1997) Stan treats this as problematic, resulting in Mary's repeat of painting (line 05) and followed by a time reference, most probably to contextualize the trouble source. There are clear problems with intelligibility here and Stan's response at line 09 is not to pursue the repair to resolution but rather to change the topic trajectory entirely to offer an evaluation of Mary's voice quality. This in itself is interesting as it enables the participants to exit the repair sequence without having to resolve the trouble (Barnes and Ferguson, 2014). There is then a significant amount of talk about Mary's saliva and Stan's report of a nurse's advice about how saliva problems may be making Mary's voice worse.

It is at line 88 that Mary attempts to return to her prior, yet to be established, topic talk about her jigsaw-painting. She does this by initiating her turn with 'so" (see Bolden, 2009; Raymond, 2004) and an explicit reference to her prior attempt-I was saying (line 88). This has parallels with Extract 1 in that she attempts to signpost to something that has 59 come earlier but not immediately prior in the con60 versation. Of course the difficulty in this instance is that what Mary has said earlier remains an unre- 61 solved trouble source and not something to which 62 Stan can be easily cued in terms of content or 63 sequential position.

As previously, Mary's attempt at establishing the 65 topic does not receive an immediate uptake by 66 Stan and results in numerous attempts to make 67 herself understood by expanding the descriptive 68 properties of the jigsaw (lines 92-104). Stan's on- 69 going problems with understanding are made clear 70 with his talk at lines 105-108. Initially he refers to 71 the use of 'that thing again' (line 106), referring to 72 a wooden pointer stick that Mary uses to press keys 73 on her VOCA. Through this talk Stan is not 74 attempting to interpret what he has heard, but sug- 75 gesting a technical resolution to his on-going dif- 76 ficulties. Mary accepts this suggestion by picking 77 up the stick. As with Extract 2 Stan takes the next 78 turn rather than allowing Mary the opportunity to 79 attempt a VOCA mediated self-repair. Through his 80 turn at line 111 he displays on-going difficulty with 81 Mary's speech and then offers a potential refer- 82 ence: 'are you still talking about ...'. The difficulty 83 here is one of ambiguity. Here he is invoking the 84 most immediately known and shared topic talk, 85 saliva, as a possible reference point. Stan's use of 86 'still' indicates that Mary's problematic talk might 87 be a continuation of something already known and 88 current. One presumable benefit of establishing 89 topic in this way is to significantly reduce the range 90 of possible topic choices to which Mary might be 91 referring. Mary's monitoring of Stan's turn in 92 progress is displayed by her negation of his 93 proposal before he even mentions the saliva 94 problem.

Through the use of 'still talking' Stan appears to 96 be aware of a potential ambiguity; that is, he is asking 97 Mary to accept or reject the possibility that she is 98 either trying to continue to talk about a prior known 99 topic or to introduce something new and yet to be 100 understood.

Extract 4-'cream or patches'. In making sense of 103 problems associated with dysarthric speech we have 104 focused on topic transition attempts by speakers with 105 dysarthria. It is entirely possible, however, for prob- 106 lems to be associated with topic transitions initiated 107 by conversation partners. In Extract 4 a difficulty 108 with sequentiality arises in part due to Molly's topic 109 transition. It is Alex's on-going reference to the prior 110 topic of talk that leads to difficulties for Molly in 111 understanding to what he is referring.

Immediately prior to this Extract Alex has com- 113 plained to Molly about his eye-cream. He has alleged 114 that nursing staff have not been applying it as regu- 115 larly as prescribed and that there may be a break- 116 down in communication between staff covering 117 different shifts. At the start of the Extract Molly 118 aligns her stance with Alex's by providing her own 119 assessment. 
Molly I don't think em half of them know what the

Alex other 「half's do †ing

$(0.6)$

Molly you remind me to put your patch on?

$(0.9)$

(looks back to $M))=$

Molly =when this is finished.

$(0.6)$

Alex (2 syllables) (one)

$(0.4)$

Molly one

Alex ( 1 syllable)

Molly on,

$(1.0)$

Alex ${ }^{\circ} \mathrm{h}$ :

Molly want one on both [sides?

Alex $[(($ head shake $))]$ (ar: : a: one)

$(0.2)$

Molly you want one

$(0.2)$

Alex ((slight head shake))( 2 syllables)

$(0.2)$

Molly one

Alex (1 syllable)

$(0.4)$

Molly en?

Alex ((slight head shake))(and)

Molly and?

Molly and?

Alex a

Molly $\quad a^{(0.2)}$

$(1.0)$

$\begin{array}{ll}\text { Alex half } & (0.2)\end{array}$

Molly one and a half?

$(0.4)$

Alex (days)

Molly $(0.2)$

Molly days

Alex ((moves left lower lip down))

$(1.3)$

Alex $\lceil(\mathrm{es})]$

Molly [what] your (.) the cream [we're on

Alex

Molly about $\uparrow$ now still?
Molly's idiomatic assessment at the start of this Extract is a possible attempt to close down the prior eye-cream complaint talk. At line 5 she produces a request regarding Alex's patch, a gradual release medication placed on the neck area to help manage excess saliva. This change from eye-cream to patch represents a transition from complainable/evaluation to future action. With no obvious uptake, Molly appends her request with a time reference at line 08 . In what follows Alex and Molly jointly produce the word "one" (lines 10 and 12) followed by what Molly interprets as 'on" (line 16). She subsequently offers an anticipatory completion (Bloch, 2011) 'want one on both sides?" (line 20) which Alex immediately negates. Molly, thus, reveals her interpretation of Alex's current action as a request for one patch on both sides of his neck. This interpretation appears to be a reasonable sequential fit with the current topic of patches.

On seeing Alex's negation and restart (line 21), Molly repeats "you want one" but this is again negated. The ensuing sequence of talk produces 'one and a half days" (lines 25-47). It is at line 52 that Molly displays her on-going uncertainty about the current topic of talk. Her reference to "cream" shows that her earlier understanding of patches may be 61 incorrect.

Extracts 2, 3 and 4 above have featured dysar- 63 thric speech output as one of the underlying con- 64 tributors to problems in understanding. These 65 difficulties have been compounded by their role in 66 topic transitions. We also recognize, however, that 67 people with progressive neurological conditions 68 may use other modalities either in combination 69 with speech or as a replacement when speech pro- 70 duction becomes too effortful. In the final two 71 Extracts topic transition troubles arise through the 72 use of finger spelling and of an on-screen emulated 73 keyboard system. In both cases the person with dys- 74 arthria has a functional alternative means of word 75 creation, but the couples involved still encounter 76 topic transition difficulties.

78

Extract 5-Mike's coming Friday. In this Extract Jean 79 attempts to initiate, through fingerspelling, a new 80 topic with the name 'Mike'. Ali shows an under- 81 standing of this after a repeat by Jean, but then com- 82 plains later on: 'give me a clue before you start 83 spelling .... 84

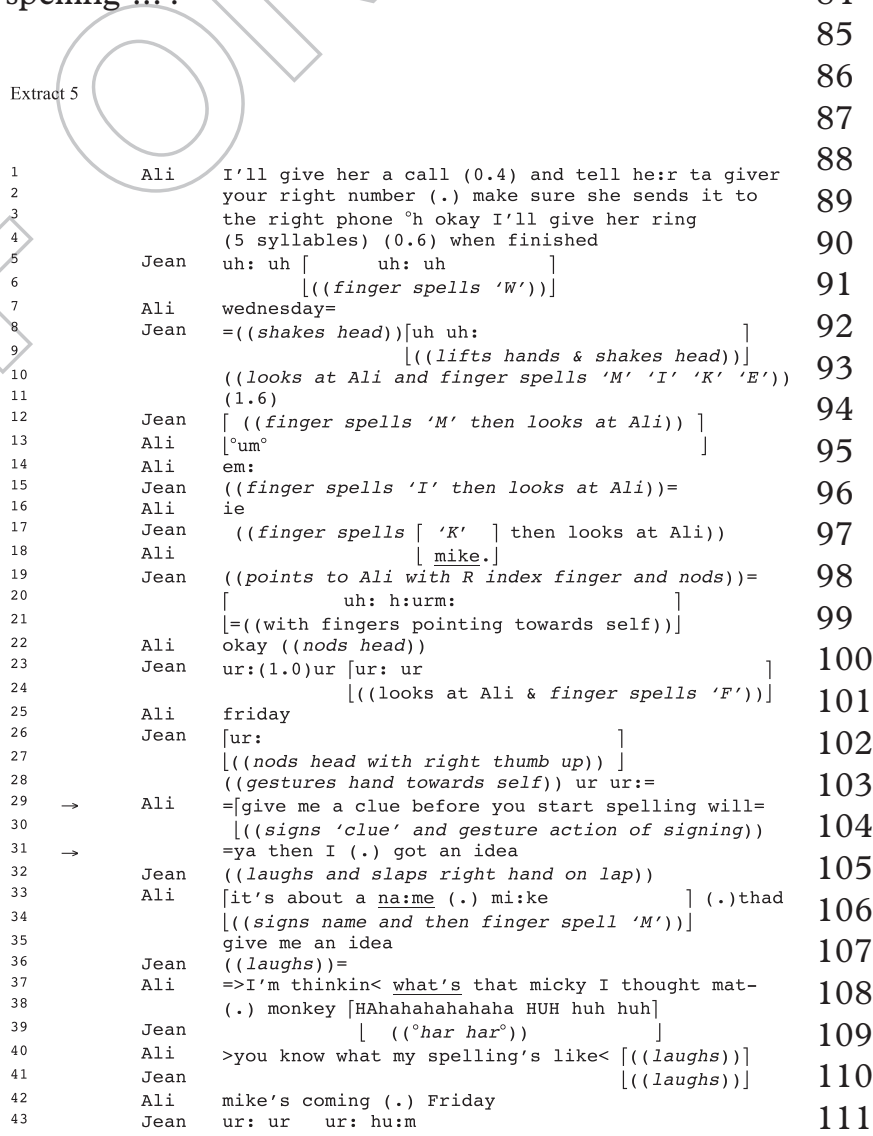

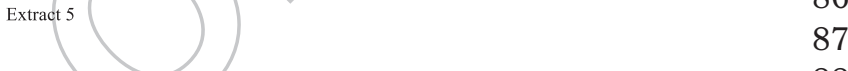

At the start of this Extract Ali talks about the cor- 114 rection of an incorrect phone number that has been 115 given to one of Jean's friends. Jean vocalizes before 116 finger spelling the letter ' $W$ '. This is interpreted by 117 Ali as 'Wednesday'. Jean rejects this interpretation 118 before re-starting her finger spelling with five 119 consecutive letters: ' $\mathrm{m}$ ' ' $\mathrm{i}$ ' ' $\mathrm{k}$ ' and 'e' (line 10). 120 
A considerable silence follows, which Jean treats as problematic through her subsequent re-doing of her prior finger spelling activity with one letter sign at a time. This spelling works in collaboration with Ali, who verbally interprets each letter name as it becomes visible (see Bloch 2005 for similarities with verbal spelling). Ali's interpretations function as legibility checks for each element of the construction in progress. As Jean completes the sign for ' $\mathrm{K}$ ' (line 17), Ali says 'Mike'. This is affirmed by Jean with a finger point and head nod movement. Jean then proceeds to point to herself and then finger spell ' $F$ ' which Ali interprets as 'Friday'. Jean confirms this interpretation as correct before gesturing with a movement that indicates herself. We later learn that this gesture is an attempt to progress the utterance already underway.

Rather than treating Jean's gesture as a contribution to an ongoing utterance, Ali, at line 29 , voices a complaint about the prior episode of interaction. She begins with a request for Jean to give her 'a clue' before she starts spelling and that this will give her 'an idea', presumably about to what it is that Jean is referring. Ali then proceeds to describe her confusion in more detail including taking some responsibility for the trouble with reference to her own spelling (line 40). It is then, at line 42, that Ali shows a complete understanding of Jean's prior utterance, possibly to enable the talk to proceed.

Of interest in this Extract is the placement of the complaint, which is subsequently treated by both participants as non-serious. Ali appears to explain the problem as an unannounced name spelling trouble. Her suggested future remedy is for Jean to produce the sign for 'name' prior to finger spelling a name itself. The benefit here is presumably to cue Ali semantically into whatever is to follow. It is noted that the complaint does not appear immediately after the name 'Mike' has been verbalized and presumably understood by Ali. Rather, Ali's complaint comes somewhat later in the sequence after Jean has completed her utterance in progress with a reference to herself and Friday. The evidence here is that Ali waits for an opportunity to evaluate Jean's finger spelling understandability only once the utterance has been finished, even though there are several opportunities for her to do so before utterance completion.

Extract 6-rubbish fire. In the final Extract, topic transition is examined in the context of AAC system output. With speech no longer functional it is common for people with MND to rely largely on an AAC device (Ball, Fager, \& Fried-Oken, 2012). In this case the use of an on-screen virtual keyboard operated by head switches enables Alex to successfully produce words and phrases. However, as with natural speech in earlier Extracts, difficulties emerge in the use of AAC within an on-going conversation. Immediately prior to this Extract, Molly and Alex have been talking about a fire drill held in Alex's 61 nursing home the day before.

Extract 6

$\begin{array}{ll}01 & \\ 02 & \\ 03 & \\ 04 & \\ 05 & \\ 06 & \\ 07 & \\ 08 & \\ 09 & \\ 10 & \\ 11 & \\ 12 & \\ 13 & \\ 14 & \\ 15 & \\ 16 & \\ 17 & \\ 18 & \\ 19 & \\ 20 & \\ 21 & \\ 22 & \\ 23 & \end{array}$

Molly right $(0.3)$ oka:y

Alex \# \# \# \# (3.0) \# \# \# \# (1.5) \# [r] \# \# (2.5) [u] \# (2.9) \# (4.8) \#\#\# \# $(1.0) \#[$ rubbish]\# = Molly $=(($ looks to Alex and back to screen $))=$

Molly $=\underline{\text { rubbish }[\text { fire? }}[(($ looks to Alex $))]=$

Alex $=\#=$

Molly $=(($ looks back to screen $))=$

Alex $=(1.0) \#[1](1.9) \quad \#=$

Molly $={ }^{\circ}$ rubbish,${ }^{\circ}=$

Alex $=\#(1.8) \# \# \#(1.0) \# \# \#(1.5) \#$ \# $(0.8)$ \# $(0.5)$ \#\# \# $(1.0)$ \# \#[w] \#\# $(2.9)$ \# [ $\leftarrow$ ] \#

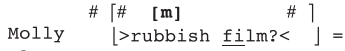

Alex $=\#$ \# $=$

Molly $=$ what $[$ was $($.$) the fire drill?]$

(0.8) $\mathrm{L}$ ((looks to Alex))

$\begin{array}{ll}\text { Alex } & ((\text { very small movement of lower right lip }))= \\ \text { Molly } & =\end{array}$ [\you. ((looks back to screen $))]$

Alex $\quad(($ smiles $))$

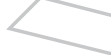

The Extract begins with Molly acknowledging the 80 occurrence of a recent fire test at Alex's nursing 81 home (line 01). Alex then proceeds to type onscreen, 82 via his head switch, the letters 'f' and 'I' (line 05) 83 which Molly attempts to complete with 'rubbish 84 fire?' (line 06). This anticipatory completion is plau- 85 sible given both the prior context of fire tests and the 86 probability of word endings based on the letters ' $\mathrm{f}$ ' 87 and 'I'. Molly's completion attempt appears to be 88 designed as a clarification request, signalled by its 89 questioning intonation. Following her completion 90 Molly looks to Alex but he provides no response and 91 continues to type selecting ' 1 ' and ' $m$ ' (lines 10-14) 92 punctuated by a typing error: 'w'. Molly then reads 93 aloud the visual display 'rubbish film' (line 15). The 94 word 'film' reveals Molly's earlier attempted antici- 95 patory completion of 'fire' to be incorrect. 96

Molly now attempts to make sense of 'rubbish 97 film' with reference to the aforementioned fire drill. 98 Alex provides a non-verbal rejection of this link (line 99 20) before Molly makes a complaint. This complaint 100 centres on Alex having changed the subject again, 101 presumably referring to a change without Molly's 102 awareness.

Molly's completion reveals an attempt to establish a 104 sequential link between current and prior talk. In terms 105 of action it transpires that Alex is offering an evaluation 106 of a movie he watched the prior evening: 'rubbish film 107 yesterday', with 'rubbish' being used in its adjective 108 form. However, Molly's initial understanding is of 109 'rubbish' in its noun form (see also Bloch and Wilkin- 110 son, 2013). This leads to her error in anticipating 'fire' 111 as Alex's intended talk. Thus, two difficulties for the 112 participants become apparent from this analysis: estab- 113 lishing an utterance ending and, of more interactional 114 impact, establishing a topic transition. It is also noted 115 that in saying 'again' (line 21), Molly is enhancing 116 the complaint by invoking a repeat offence. Molly 117 appears to be using similar previous unmarked topic 118 transitions as additional evidence to add weight to the 119 moral worthiness of her present, albeit non-serious, 120 
complainable, as evidenced by Alex's smile at line 23 . In summary, Molly is saying here: you have changed the topic/subject without indicating to me that you are doing so and this gives cause for non-serious complaint/teasing. So, in addition to topic transitions as a problem for people with moderate-to-severe dysarthria speech we also have evidence that such problems can arise for people using AAC systems.

\section{Discussion}

In this paper we have used the principles of Conversation Analysis to examine topic transitions within the context of dysarthric speech and AAC production. Specifically, we have analysed episodes of interaction from three dyads where there is a problematic understanding of topic reference. In each Extract the nature of the trouble source, produced by the person with dysarthria, is characterized by a break in sequentiality between the current turn's topic and that which has come immediately prior. Further, in many of the Extracts the co-participant invokes topic ambiguity as part of the repair activity, displaying an explicit orientation to topic in order to progress to resolution.

In exploring why topic transitions in dysarthria prove problematic we can look to a number of features, including speech intelligibility, reduction in the use of transition markers, ambiguous references and disjunctive markers. In the first instance there is the occurrence of unintelligible or at least partially intelligible speech. The importance of this should not be under-estimated. In Extracts 2, 3 and 4 the speech of the person with dysarthria is clearly treated as problematic by the recipient. This is revealed through other-initiated repair constructions such as 'I didn't get that' (Extract 2) and 'I'm not certain what you're saying' (Extract 3 ).

Looking beyond speech intelligibility, however, we can also see a reduction in or absence of explicit transition markers. In Extract 1 there is a clear construction being used to signpost the direction and reference of the talk to follow. Ali (Extract 1) says 'going back to' as a preface to 'the potty training'. There are no such topic transition markers in Extracts 2, 4, 5 and 6. In each of these Extracts, the speaker with dysarthria constructs a turn or contribution that neither marks a clear break from the immediately prior topic talk nor looks forward to display that a new topic is being initiated. In these terms the risk of a problematic understanding relating to topic transition may be increased. However, it is not the case that dysarthric speech/AAC output equates to a complete absence of topic transition work. In Extract 3 Mary does attempt to do just this: 'so I was saying about my painting'. The problem with this attempt is that it is unintelligible as well as making reference to prior talk that Stan has yet to understand. So, aside from Mary's overall intelligibility the action of topic transition has yet to be established. 61 Stan's trouble is not only that he cannot adequately 62 hear Mary's speech, but also what it is she is attempt- 63 ing to do with her turn.

The unproblematic transition marker in Extract 165 is characterized by orientation to topic shift or change 66 in the form of word selection. It also features changes 67 in intonation and placement with reference to prior 68 talk. It is likely that topic transition is far more vul- 69 nerable to problematic understandings when these 70 additional features are also compromised, particu- 71 larly given the importance of prosody to topic shift- 72 ing (Couper-Kuhlen, 2004; Zellers, 2012).

In addition to the absence of topic transition 74 markers we note ambiguity of reference as a specific 75 problem, specifically when the topic is not clear. This 76 is displayed in some instances as the repair sequence 77 is played out. In Extract 4, for example, Alex's pro- 78 duction of 'one' is initially treated by Molly as a pro- 79 noun reference to patch: 'want one (patch) on both 80 sides?', with patches having been topicalized by her 81 earlier topic transition turn. Molly subsequently real- 82 izes that Alex is using 'one' to reference time as in 83 'one and half days' since he has had any eye-cream. 84 In this case the meaning of Alex's 'one' can only be 85 correctly understood in the context of his own prior 86 topic talk of eye-cream, not Molly's more recently 87 introduced topic of patches. A similar issue arises 88 with Alex's AAC output (Extract 6). One of the rea- 89 sons these problems arise is due to the nature of the 90 turn constructions. Unlike the other dyads, Alex and 91 Molly have adapted their turn designs to minimize 92 the risks associated with lengthy dysarthric speech 93 turns (Bloch, 2005). In reducing his verbal output 94 to single or paired letter names or words, the speech 95 sounds in each turn are more available for examina- 96 tion by Molly and, as a result, are more directly 97 repairable (Collins \& Markova, 1995). Further, 98 Molly has the option of offering an anticipatory 99 completion (Bloch, 2011) of these constructions. 100 The risk, however, is an incorrect completion and it 101 is this problem associated with the wrong comple- 102 tion of an utterance in progress that characterizes the 103 troubles in Extracts 4 and 6. Clarke and Wilkinson 104 (2008) provide a similar example in which the antic- 105 ipatorily completed 'green' is initially treated as an 106 adjective before being amended to 'greens' to con- 107 firm its noun status within an ongoing VOCA utter- 108 ance. The evidence indicates that words constructed 109 over several turns are more prone to these types of 110 troubles, particularly with respect to the co-partici- 111 pant's opportunity to anticipate the word prior to its 112 completion.

Finally, we note that all of the transitions analysed 114 in this paper are disjunctive (Button \& Casey, 1985); 115 that is, the attempted topic changes are not gradual 116 but have clear boundaries. These topic breaks 117 between the trouble source turns and the immedi- 118 ately prior talk appear to add to the difficulties expe- 119 rienced by the participants. 


\section{Problematic topic transition as a complainable}

The evidence we have presented indicates that troubles in dysarthric talk are repaired rather than abandoned (Barnes \& Ferguson, 2014), but, while the focus of this paper is not on trouble resolution per se, it is possible to comment on topic transition orientation by the co-participants. In all of the trouble Extracts (2-6) we note that the co-participant makes explicit reference to topic. Specifically they treat the problem as complainable or worthy of critical comment in some way. In Extracts 3 and 4 topic reference is used in pursuit of the repair resolution as evidenced by the co-participant seeking clarification, as in Extract 4, 'the cream we're on about now still?'. However, in Extracts 2, 5 and 6, the reference to topic change is more accusatory, albeit in a non-serious manner. These Extracts are interesting in that they reveal one way in which topic transition problems are experienced. In each of these cases there is an element of complainability, as in Extract 2: 'what's that got to do with my double-glazing?'. This may well resonate with Robinson's (2006) examination of accountability. The non-serious nature of these interactions deserves further investigation, particularly in relation to face-saving and the moral treatment of competence in communication disability.

Whilst the extracts presented in this paper and the dyads from which they have been drawn are necessarily selective, the authors consider them representative of the whole data set. The incidence of troubles and repair will vary across each conversation and each dyad, but the evidence here shows that participants are organized in their identification and resolution of troubles, even when these problems lead to lengthy repair sequences.

\section{Implications and conclusions}

In this paper we have focused on problematic topic transition within an environment of dysarthric speech in conversation. We have shown how attempts to change or shift topic are vulnerable to problematic sequential understandings and how participants resolve such problems. We have also considered the ways in which responsibility for these problems are raised. There is evidence that people with severely dysarthric speech do attempt topic change (see Extract 3) and we have preliminary data to show that some participants can adapt their action-design following feedback from their conversation partner. In Extract 5, for example, Ali asks her mother Jean to give her a clue before she starts finger spelling. We observe that later in the same conversation Jean does indeed signal 'name' prior to finger spelling a person's name. These initial observations will be reported in future publications following further data analysis. Further work is required to establish the role of topic organization in dysarthria therapy and its viability as an outcome measure, but there is encouraging evi- 61 dence from the field of aphasia indicating that 62 problematic topic transition is amenable to success- 63 ful intervention (Wilkinson et al., 2011). 64

We have noted that topic transition may not just 65 rely on words, but also appropriate timing, prosody 66 and non-verbal actions. People with associated phys- 67 ical disabilities and those using AAC systems may 68 face additional but not insurmountable challenges. 69 The degree to which people with dysarthria can inte- 70 grate more explicit topic transition actions in their 71 talk remains to be seen. $\quad 72$

The organization of topic remains an elusive con- 73 cept that defies easy categorization and boundaries. 74 Nevertheless, the evidence presented here shows that 75 topic management in talk can have a significant 76 impact on the relative success or otherwise of dysar- 77 thria and AAC-in-interaction. We show here that the 78 organization of talk is vulnerable to problems within 79 a specific environment. It is likely that further analy- 80 sis of talk using the methods of CA, particularly with 81 reference to change over time, will reveal other envi- 82 ronments in the organization of conversation that are 83 equally if not more prone to troubles.

Declaration of interest: The authors report no 86 conflicts of interest. The authors alone are respon- 87 sible for the content and writing of the paper. 88

\section{References}

Ball, L. J., Fager, S., \& Fried-Oken, M. (2012). Augmentative and alternative communication for people with progressive neuromuscular disease. Physical Medicine and Rehabilitation Clinics of North America, 23, 689-699.

Barnes, S., \& Ferguson, A. (2014). Conversation partner responses to problematic talk produced by people with aphasia: Some alternatives to initiating, completing, or pursuing repair. Aphasiology, 1-22.

Barnes, S. E., Candlin, C. N., \& Ferguson, A. (2013). Aphasia and topic initiation in conversation: a case study. International fournal of Language \& Communication Disorders, 48, 102-114.

Bloch, S. (2005). Co-constructing meaning in dysarthria: word and letter repetition in the construction of turns. In K. Richards, \& P. Seedhouse (Eds.), Applying Conversation Analysis (pp. 38-55). Basingstoke: Palgrave Macmillan.

Bloch, S. (2006). Trouble sources and repair in acquired dysarthria and 105 communication aid use: A conversation analysis study. Unpublished 106 doctoral dissertation. (PhD), University of London, London.

Bloch, S. (2011). Anticipatory other-completion of augmentative and alternative communication talk: A conversation analysis study. Disability and Rehabilitation, 33, 261-269.

Bloch, S. (2013). Conversation and interaction in degenerative 110 diseases. In K. M.Yorkston, R. M. Miller \& Strand, E. A.(Eds.), Management of Speech and Swallowing in Degenerative Diseases, 3rd ed. (pp. 195-220). Austin, Texas: Pro-Ed.

Bloch, S., \& Wilkinson, R. (2004). The Understandability of AAC: 113 A Conversation Analysis Study of Acquired Dysarthria. AAC: 114 Augmentative and Alternative Communication, 20, 272-282. 115

Bloch, S., \& Wilkinson, R. (2009). Acquired dysarthria in conver- 116 sation: Identifying sources of understandability problems. International Fournal of Language and Communication Disorders, 44, 769-783.

Bloch, S., \& Wilkinson, R. (2011). Acquired dysarthria in conver- 119 sation: Methods of resolving understandability problems. (1)

4

.

2


International fournal of Language \& Communication Disorders, 46, 510-523.

Bloch, S., \& Wilkinson, R. (2013). Multiple troubles and repair in voice output communication aid-mediated interaction. In N. Norén, C. Samuelsson, \& C. Plejert (Eds.), Aided Communication in Everyday Interaction (pp. 95-126). Guildford: J \& R Press.

Bolden, G. B. (2009). Implementing incipient actions: The discourse marker 'so' in English conversation. Fournal of Pragmaitcs, 41, 974-998.

Button, G., \& Casey, N. (1984). Generating topic: the use of topic initial elicitors. In J. M. Atkinson, \& J. Heritage (Eds.), Structures of Social Action (pp. 167-190). Paris: Cambridge University Press.

Button, G., \& Casey, N. (1985). Topic Nomination and Topic Pursuit. Human Studies, 8, 3-55.

Button, G., \& Casey, N. (1988/89). Topic Initiation: Business-atHand. Research on Language E Social Interaction, 22, 61-92.

Clarke, M., \& Wilkinson, R. (2007). Interaction between children with cerebral palsy and their peers 1: Organizing and understanding VOCA use. Augmentative and Alternative Communication, 23, 336-348.

Clarke, M., \& Wilkinson, R. (2008). Interaction between children with cerebral palsy and their peers 2: Understanding initiated VOCA-mediated turns. Augmentative and Alternative Communication, 24, 3-15.

Clarke, M., Bloch, S., \& Wilkinson, R. (2013). Speaker transfer in children's peer conversation: completing communicationaid-mediated contributions. Augmentative and Alternative Communication, 29, 37-53.

Collins, S., \& Markova, I. (1995). Complementarity in the construction of a problematic utterance in conversation. In I. Markova, C. F. Graumann, \& K. Foppa (Eds.), Mutualities in Dialogue (pp. 238-263). Cambridge: Cambridge University Press.

Collins, S., \& Markova, I. (1999). Interaction between impaired and unimpaired speakers: Inter-subjectivity and the interplay of culturally shared and situation specific knowledge. British Fournal of Social Psychology, 38, 339-368.

Couper-Kuhlen, E. (2004). Prosody and sequence organization in English conversation. In E. Couper-Kuhlen, \& C. E. Ford (Eds.), Sound Patterns in Interaction (pp. 335-376). Amstersdam: John Benjamins.

Drew, P. (1997). 'Open' class repair initiators in response to sequential sources of trouble in conversation. Fournal of Pragmatics, 28, 69-101.

Drew, P., \& Holt, E. (1998). Figures of speech: Figurative expressions and the management of topic transition in conversation. Language in Society, 27, 495-522.

Garcia, L. J., \& Joanette, Y. (1997). Analysis of conversational topic shifts: a multiple case study. Brain Lang, 58, 92-114.

Griffiths, S., Barnes, R., Britten, N., \&Wilkinson, R. (2011). Investigating interactional competencies in Parkinson's disease: the potential benefits of a conversation analytic approach. International Fournal of Language \& Communication Disorders, 46, 497-509.

Griffiths, S., Barnes, R., Britten, N., \& Wilkinson, R. (2012). Potential Causes and Consequences of Overlap in Talk between Speakers with Parkinson's Disease and Their Familiar Conversation Partners. Seminars in speech and language, 33, 27-43.

Jefferson, G. (1984a). On stepwise transition from talk about a trouble to inappropriately next-positioned matters. In J. M.

\section{Supplementary material available online}

Supplementary Appendix to be found online at http://informahealthcare.com/doi/abs/10.3109/ 17549507.2014 .979879 .
Atkinson, \& J. Heritage (Eds.), Structures of Social Action: stud- 61 ies in conversation analysis (pp. 191-222). Paris: Cambridge 62 University Press.

Jefferson, G. (1984b). Transcript Notation. In J. M. Atkinson, \& J. Heritage (Eds.), Structures of Social Action (pp. ix-xvi). Cambridge: Cambridge University Press.

Laakso, M., \& Klippi, A. (1999). A closer look at the 'hint and guess' sequences in 345-363.

Maynard, D. G. (1980). Placement of topic changes in conversation. Semiotica, 30, 263-290.

Orange, J. B., Lubinski, R. B., \& Higginbotham, D. J. (1996) 70 Conversational repair by individuals with dementia of the 71 Alzheimer's type. Fournal of Speech Hearing Research, 39, 72 881-895.

Raymond, G. (2004). Prompting action: The stand-alone "so" in 73 ordinary conversation. Research on Language and Social Inter- 74 action, 7, 185-218.

Robinson, J. D. (2006). Managing trouble responsibility and rela- 76 tionships during conversational repair. Communication Mono- 77 graphs, 72, 137-161.

Rutter, B. (2009). Repair sequences in dysarthric conversational speech: A study in interactional phonetics. Clinical Linguistics and Phonetics, 23, 887-900.

Rutter, B. (2010). On the use of the term 'repair' and its application to disordered conversational speech. Fournal of Interactional Research in Communication Disorders, 1, 199-216.

Sacks, H. (1992). Lectures on Conversation. Oxford: Blackwell.

Saldert, C., Ferm, U., \& Bloch, S. (2014). Semantic trouble sources and their repair in conversations affected by Parkin- 8 son's disease. International fournal of Language E Communica- 86 tion Disorders, 49, 710-721.

Saldert, C., \& Hartelius, L. (2011). Echolalia or functional repetition in conversation - a case study of an individual with Huntington's disease. Disability and Rehabilitation, 33, 253-260.

Saldert, C., Ferm, U., \& Bloch, S. (in press). Semantic trouble 91 sources and their repair in conversations affected by Parkinson's disease. International fournal of Language E Communication Disorders.

Schegloff, E. A. (1979). The relevance of repair to syntax-forconversation. Syntax and Semantics, 12, 261-286.

Schegloff, E. A. (1997). Practices and actions: Boundary cases of 9 other-initiated repair. Discourse Processes, 23, 499-545.

Schegloff, E. A. (2013). Ten operations in self-inititated, sameturn repair. In M. Hayashi, G. Raymond, \& J. Sidnell (Eds.), Conversational Repair and Human Understanding (pp. 41-70). New York: Cambridge University Press.

Schegloff, E. \& Sacks, H. (1973). Opening up closings. Semioticas $7,289-327$

Schegloff, E., Jefferson, G., \& Sacks, H. (1977). The preference for self-correction in the organization of repair in conversation. Language, 53, 361-382.

Sidnell, J. (2010). Conversation Analysis: An Introduction. Chichester: Wiley-Blackwell.

Wilkinson, R., Lock, S., Bryan, K., \& Sage, K. (2011). Interaction-focused intervention for acquired language disorders: Facilitating mutual adaptation in couples where one partner has aphasia. International fournal of Speech-Language Pathology, 13, 74-87.

Zellers, M. (2012). Prosodic variation for topic shift and other functions in local contrasts in conversation. Phonetica, 69, 231-253. 63 64 65 67 68 68

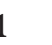

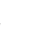

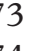
75 75
76 77 78 79 81 82 83 84 85 86 87 88 88
89 90 91 92 93 94 95 96 97 98 99 100 
Supplementary material for Bloch, S. et al. (2014). Problematic topic transitions in dysarthric conversation. 61

International fournal of Speech-Language Pathology, 2014; doi: 10.3109/17549507.2014.979879. 62

Appendix: Key to transcription symbols

\begin{tabular}{|c|c|}
\hline - & $\begin{array}{l}\text { a large left-hand bracket links an ongoing utterance with an overlapping } \\
\text { utterance or non-verbal action point where the overlap/simultaneous non- } \\
\text { verbal action begins. }\end{array}$ \\
\hline & $\begin{array}{l}\text { a large right-hand bracket marks where overlapping } \\
\text { utterances/simultaneous non-verbal action stops overlapping. }\end{array}$ \\
\hline$=$ & $\begin{array}{l}\text { an equals sign marks where there is no interval between adjacent } \\
\text { utterances. }\end{array}$ \\
\hline$()$. & $\begin{array}{l}\text { a full stop in single brackets indicates an interval of less than one tenth of a } \\
\text { second in the stream of talk. }\end{array}$ \\
\hline$(0.6)$ & $\begin{array}{l}\text { a number in single brackets indicates the length, in tenths of a second, of a } \\
\text { pause in the talk. }\end{array}$ \\
\hline oh: & $\begin{array}{l}\text { a colon indicates an extension of the sound or syllable it follows (more } \\
\text { colons prolong the stretch). }\end{array}$ \\
\hline • & $\begin{array}{l}\text { a full stop indicates a stopping fall in tone, not necessarily the end of a } \\
\text { sentence. }\end{array}$ \\
\hline & a comma indicates a continuing intonation, \\
\hline ? & a question mark indicates a rising inflection, not necessarily a question. \\
\hline$!$ & $\begin{array}{l}\text { an exclamation mark indicates an animated tone, not necessarily an } \\
\text { exclamation. }\end{array}$ \\
\hline but- & a single dash indicates a halting, abrupt cut-off to a word or part of a word. \\
\hline 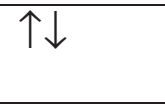 & $\begin{array}{l}\text { marked rising and falling shifts in intonation are indicated by upward and } \\
\text { downward pointing arrows immediately prior to the rise or fall. }\end{array}$ \\
\hline$\underline{\text { stress }}$ & underlining indicates emphasis. \\
\hline${ }^{\circ} \mathrm{no}^{\circ}$ & $\begin{array}{l}\text { degree signs indicate a passage of talk which is quieter than surrounding } \\
\text { talk. }\end{array}$ \\
\hline TALK & $\begin{array}{l}\text { capital letters indicate talk delivered at a louder volume than surrounding } \\
\text { talk. }\end{array}$ \\
\hline heh & $\begin{array}{l}\text { indicates discernible aspiration or laughter (the more hs the longer the } \\
\text { aspiration/laughter). }\end{array}$ \\
\hline fu(h)n & $\begin{array}{l}\text { an h in single brackets marks discernible aspiration or laughter within a } \\
\text { word in an utterance. }\end{array}$ \\
\hline${ }^{\circ} \mathrm{h}$ & discernible inhalation (the more hs the longer the inhalation). \\
\hline$>$ talk $<$ & $\begin{array}{l}\text { lesser than/greater than signs indicate sections of an utterance delivered at a } \\
\text { greater speed than the surrounding talk. }\end{array}$ \\
\hline$(($ nods $))$ & $\begin{array}{l}\text { italicized text in double brackets represents a gloss or description of some } \\
\text { non-verbal aspect of the talk, and is linked to simultaneous talk with large } \\
\text { brackets (see above). }\end{array}$ \\
\hline$(\operatorname{dog})$ & $\begin{array}{l}\text { single brackets containing either a word, phrase or syllable count (if } \\
\text { utterance is very unclear) mark where target item(s) is/are in doubt. }\end{array}$ \\
\hline \# & indicates an onscreen AAC selection. \\
\hline [u] & $\begin{array}{l}\text { bold text in square brackets represents AAC onscreen letter or word } \\
\text { display. }\end{array}$ \\
\hline
\end{tabular}

